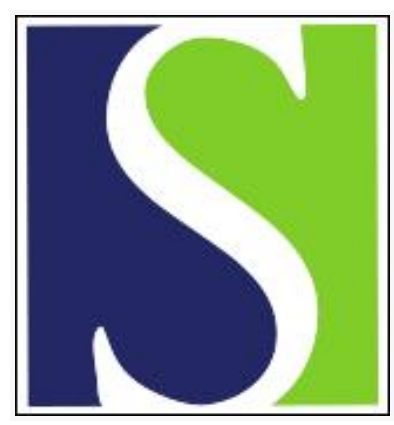

Scand J Work Environ Health 2002;28(1):42-48

https://doi.org/10.5271/sjweh.645

Issue date: Feb 2002

Occupational exposure to magnetic fields in case-referent studies of neurodegenerative diseases

by Noonan CW, Reif JS, Yost M, Touchstone J

Affiliation: Agency for Toxic Substances and Disease Registry, 1600 Clifton Road, Mailstop E-31, Atlanta, GA 30333, USA. cnoonan@cdc.gov

Refers to the following text of the Journal: 1998;24(1):46-53

The following article refers to this text: 2017;43(3):197-209

Key terms: Alzheimer's disease; amyotrophic lateral sclerosis; case-referent study; electrical occupation; job-exposure matrix; magnetic fields; neurodegenerative disease; occupational exposure; Parkinson's disease

This article in PubMed: www.ncbi.nlm.nih.gov/pubmed/11871851

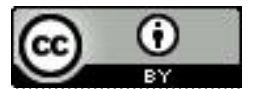




\title{
Occupational exposure to magnetic fields in case-referent studies of neurodegenerative diseases
}

\author{
by Curtis W Noonan, PhD, ${ }^{1}$ John S Reif, DVM, ${ }^{1}$ Michael Yost, PhD, ${ }^{2}$ Jennifer Touchstone, MS ${ }^{2}$
}

\begin{abstract}
Noonan CW, Reif JS, Yost M, Touchstone J. Occupational exposure to magnetic fields in case-referent studies of neurodegenerative diseases. Scand J Work Environ Health 2002;28(1):42-48.

Objectives Case-referent studies of Alzheimer's disease, amyotrophic lateral sclerosis, and Parkinson's disease were conducted to explore the relationship between these neurodegenerative diseases and occupational exposure to magnetic fields. Three methods of exposure assessment were used for the comparison, and the consistency of findings between these approaches was evaluated.

Methods Separate case-referent sets were formed from among recorded deaths of males in the state of Colorado for the years 1987 through 1996. The following three methods of exposure assessment were used: a dichotomous grouping of electrical versus nonelectrical occupations, a three-tiered grouping of potential magnetic-field exposure based on a combination of job title and industry, and categories of exposure based on the means of the magnetic fields estimated from a job-exposure matrix.

Results A positive association was observed for Parkinson's disease with all the methods of magnetic-field exposure assessment, the odds ratio (OR) for the highest category in the job-exposure matrix being 1.50 [95\% confidence interval (95\% CI) 1.02-2.19]. Amyotrophic lateral sclerosis was associated with a history of electrical occupations (OR 2.30, 95\% CI 1.29-4.09) but not with magnetic-field exposure as estimated by the job-exposure matrix. No consistent associations with magnetic fields were observed for Alzheimer's disease.

Conclusions This study provides some support for an association between occupational magnetic-field exposure and Parkinson's disease, but the findings are novel and require replication. Associations with the other neurodegenerative diseases were inconsistent and dependent on the method of exposure assessment.
\end{abstract}

Key terms Alzheimer's disease, amyotrophic lateral sclerosis, electrical occupations, job-exposure matrix, Parkinson's disease.

Recent epidemiologic studies of occupational exposure to magnetic fields have found evidence of an increased risk for neurodegenerative diseases. Several investigations have observed an association between magneticfield exposure and a risk of amyotrophic lateral sclerosis (1-6). Persons employed in occupations considered to have medium-to-high exposure to magnetic fields have also been shown to be at increased risk for Alzheimer's disease (7-9), but this finding has not been observed consistently $(1,2,6)$. Currently, there is no strong support for a similar association with Parkinson's disease $(1,2,6)$, but welders, who have high exposures to magnetic fields, were overrepresented among the cases in one study (10).

We conducted death-certificate-based case-referent analyses of these outcomes using the following three approaches to assess exposure: a dichotomous grouping of electrical versus nonelectrical occupations, a threetiered grouping of potential magnetic-field exposure based on a combination of job title and industry, and estimates of mean magnetic-field values from a job-exposure matrix. Within each case-referent study dataset, we evaluated the consistency of results obtained for the three methods of exposure assessment and identified job titles that accounted for the disparities.

\section{Subjects and methods}

\section{Study population}

Death certificate data were collected from the Vital Statistics Unit of the Colorado Department of Public Health

1 Department of Environmental Health, Colorado State University, Colorado, United States.

2 Department of Environmental Health, University of Washington, Washington, United States.

Reprint requests to: Dr Curtis W Noonan, Agency for Toxic Substances and Disease Registry, 1600 Clifton Road, Mailstop E31, Atlanta, GA 30333, USA. [E-mail: cnoonan@cdc.gov] 
and Environment. Three separate case-referent sets were formed from among recorded deaths for males in the years 1987 through 1996. Cases were selected based on any mention of Alzheimer's disease [International Classification of Diseases (ICD) code 331.0), amyotrophic lateral sclerosis (ICD code 335.2), or Parkinson's disease (ICD code 332.0)]. In an attempt to reduce the the number of early onset cases of presumed familial origin, the inclusion of persons with Alzheimer's disease was restricted to an age at death of 60 years or more. Cases of amyotrophic lateral sclerosis and Parkinson's disease were selected with an age-at-death restriction of 30 years or more to allow for sufficient occupational exposure.

Male referents were selected separately for each disease group and were frequency matched by 5 -year age intervals and year of death. Because of the small number of cases of amyotrophic lateral sclerosis, we used a 4:1 referent-to-case ratio for this analysis. A 1:1 referentto-case ratio was employed for the other diseases. These selection criteria provided an $80 \%$ power to detect an odds ratio (OR) of 2.0 at the $95 \%$ confidence level for a dichotomous exposure. Death certificates with a mention of leukemia, brain cancer, or breast cancer were ineligible for referent selection since magnetic fields are a putative risk factor for these diseases. Death certificates with any mention of the three neurodegenerative diseases of interest were also ineligible for referent selection. The descriptive data studied are presented in table 1 for the cases and referents for each disease. For all three case-referent groups, there was a higher proportion of cases among non-Hispanic whites, those with 12 or more years of education, and those with professional or managerial occupations.

\section{Exposure assessment}

All death certificates included the person's primary lifetime occupation and industry, classified with 3-digit codes based on the 1980 United States Bureau of Census Classified Index of Industries and Occupations (11). For male decedents in Colorado during 1987 through 1996, less than $2 \%$ of the death certificates had the occupation recorded as unknown.

We assessed risk using three systems of exposure classification. The first method applied a dichotomous exposure classification used previously to identify persons with electrical occupations as having probable high exposure to magnetic fields $(1,12,13)$. The electrical occupations used in these studies included electrical and electronic technicians and engineers, repairers of electronic equipment, telephone and telephone line installers and repairers, electricians, electric power installers and repairers, supervisors of electricians and power transmission installers, power plant operators, motion picture projectionists, and broadcast equipment operators $(1,12,13)$.

The second method used a tiered assignment of exposure that has been employed in death-certificate-based case-referent studies of magnetic-field exposure and brain cancer $(14,15)$. This approach classified people into one of four exposure categories according to a combination of occupation and industry codes. For this study, the two highest categories (definite and probable magnetic-field exposure) were combined due to the low number of persons found in the second tier of exposure.

In the third method of exposure assessment, a population-based job-exposure matrix was used to assess exposures to power-frequency magnetic fields. The jobexposure matrix compiled approximately 2400 magnetic-field measurements taken in 10 studies in the United States, Sweden, New Zealand, Finland, and Italy. A large fraction (97\%) of the magnetic-field data collected with this matrix came from full-shift personal sampling; spot measurements comprised only $3 \%$ of the

Table 1. Descriptive data for the male cases and referents for Alzheimer's disease, amyotrophic lateral sclerosis, and Parkinson's disease in Colorado, 1987-1996.

\begin{tabular}{|c|c|c|c|c|c|c|}
\hline \multirow[t]{2}{*}{ Attribute } & \multicolumn{2}{|c|}{$\begin{array}{l}\text { Alzheimer's } \\
\text { disease a }^{\text {a }}\end{array}$} & \multicolumn{2}{|c|}{$\begin{array}{l}\text { Amyotrophic } \\
\text { lateral sclerosis }{ }^{\text {b }}\end{array}$} & \multicolumn{2}{|c|}{$\begin{array}{l}\text { Parkinson's } \\
\text { disease }{ }^{c}\end{array}$} \\
\hline & $\begin{array}{l}\text { Cases } \\
(\mathrm{N})\end{array}$ & $\begin{array}{l}\text { Referents } \\
\text { (N) }\end{array}$ & $\begin{array}{l}\text { Cases } \\
\text { (N) }\end{array}$ & $\begin{array}{l}\text { Referents } \\
\text { (N) }\end{array}$ & $\begin{array}{l}\text { Cases } \\
(\mathrm{N})\end{array}$ & $\begin{array}{l}\text { Referents } \\
\text { (N) }\end{array}$ \\
\hline \multicolumn{7}{|l|}{ Age at death } \\
\hline $\begin{array}{r}30-39 \text { years } \\
40-49 \text { years } \\
50-59 \text { years } \\
60-69 \text { years } \\
70-79 \text { years } \\
\geq 80 \text { years }\end{array}$ & $\begin{array}{r}- \\
- \\
- \\
80 \\
489 \\
987\end{array}$ & $\begin{array}{r}- \\
- \\
- \\
80 \\
489 \\
987\end{array}$ & $\begin{array}{r}7 \\
21 \\
43 \\
95 \\
98 \\
48\end{array}$ & $\begin{array}{r}28 \\
84 \\
172 \\
380 \\
392 \\
192\end{array}$ & $\begin{array}{r}1 \\
1 \\
10 \\
80 \\
553 \\
832\end{array}$ & $\begin{array}{r}1 \\
1 \\
10 \\
80 \\
553 \\
832\end{array}$ \\
\hline \multicolumn{7}{|l|}{ Race } \\
\hline $\begin{array}{l}\text { Non-Hispanic } \\
\text { white } \\
\text { Other }\end{array}$ & $\begin{array}{r}1532 \\
24\end{array}$ & $\begin{array}{r}1504 \\
52\end{array}$ & $\begin{array}{r}309 \\
3\end{array}$ & $\begin{array}{r}1197 \\
51\end{array}$ & $\begin{array}{r}1455 \\
22\end{array}$ & $\begin{array}{r}1441 \\
36\end{array}$ \\
\hline \multicolumn{7}{|l|}{ Education d } \\
\hline $\begin{array}{l}\geq 12 \text { years } \\
<12 \text { years }\end{array}$ & $\begin{array}{l}797 \\
445\end{array}$ & $\begin{array}{l}740 \\
483\end{array}$ & $\begin{array}{r}200 \\
61\end{array}$ & $\begin{array}{l}715 \\
310\end{array}$ & $\begin{array}{l}800 \\
398\end{array}$ & $\begin{array}{l}716 \\
475\end{array}$ \\
\hline \multicolumn{7}{|l|}{ Year of death } \\
\hline $\begin{array}{l}1987-1991 \\
1992-1996\end{array}$ & $\begin{array}{l}717 \\
839\end{array}$ & $\begin{array}{l}717 \\
839\end{array}$ & $\begin{array}{l}148 \\
164\end{array}$ & $\begin{array}{l}592 \\
656\end{array}$ & $\begin{array}{l}647 \\
830\end{array}$ & $\begin{array}{l}647 \\
830\end{array}$ \\
\hline \multicolumn{7}{|c|}{ Occupational grouping e } \\
\hline $\begin{array}{l}\text { Managerial or } \\
\text { professional } \\
\text { Technical, etc } \\
\text { Service, etc }\end{array}$ & $\begin{array}{l}410 \\
295 \\
851\end{array}$ & $\begin{array}{l}368 \\
256 \\
932\end{array}$ & $\begin{array}{r}114 \\
61 \\
137\end{array}$ & $\begin{array}{l}283 \\
227 \\
738\end{array}$ & $\begin{array}{l}405 \\
297 \\
775\end{array}$ & $\begin{array}{l}358 \\
240 \\
879\end{array}$ \\
\hline
\end{tabular}

a Total number: 1556 cases and 1556 referents.

${ }^{b}$ Total number: 312 cases and 1248 referents.

c Total number: 1477 cases and 1477 referents.

d There were no educational data available for 1987-1988 records.

e Occupations were grouped into the following broad categories: (i) managerial or professional, (ii) technical or sales or administrative support, (iii) service or farming or craft or repair or operators or fabricators or laborers. 
total data of the matrix. Job descriptions from each study were coded into the 1980 Standard Occupational Classifications and then translated to the 1980 job categories of the United States Bureau of the Census. The job categories recorded on the death certificates were assigned workday-average geometric mean magnetic-field values from the job-exposure matrix. Based on these values, people were assigned to one of four exposure groups determined by cut points that have been used previously in epidemiologic studies (9). The highest exposure category $(\geq 0.30 \mu \mathrm{T})$ captured the top $4-6 \%$ of the cases for the three diseases studied. The job-exposure matrix contained geometric mean values for $85 \%$ of the job titles in our data sets, accounting for 79-84\% of the persons. The proportions of cases and referents for which the data of the job-exposure matrix were missing were similar.

\section{Data analyses}

We performed unconditional logistic regression with SAS 6.12 (SAS Institute, Inc., Cary, NC) on each casereferent group to test for associations between each disease and each of three magnetic-field exposure methods. All the odds ratios for the magnetic-field exposure methods were adjusted for age, race, and a social class variable. Social class was assigned to three levels that were based on broad occupational categories. This approach was taken to control for socioeconomic status as a potential confounder rather than years of education since data for education were not available for the first 2 years of our study. There were no substantial changes in the risk estimates when education was included in the analyses. We also explored the effect of classifying by specific job titles posthoc to determine how different classification schemes may have accounted for varied results.

\section{Results}

The results of the analyses of each case-referent group are shown using three different approaches to exposure assessment (table 2). When magnetic-field exposure was defined by electrical occupations (method 1) or the jobexposure matrix (method 3), we did not observe any elevation in risk for Alzheimer's disease. With the use of a combination of job title and industry (method 2), a weak imprecise association was found for Alzheimer's disease in the highest category of exposure [adjusted OR $1.21,95 \%$ confidence interval $(95 \%$ CI) $0.83-1.76]$. A posthoc review of the occupational distribution of the cases and referents indicated that the change in the risk estimate with this method was due primarily to the inclusion of aerospace engineers in the high-exposure stratum and the reassignment of electrical technicians not employed in the utility or telecommunications industry to a lower stratum.

For amyotrophic lateral sclerosis, there was an elevation in risk using both methods 1 and 2 (adjusted OR $2.30,95 \%$ CI 1.29-4.09, and 1.75, 95 CI 1.00-3.06, respectively). No elevated risk for amyotrophic lateral sclerosis was observed when the job-exposure matrix

Table 2. Adjusted odds ratios (OR) for each case-referent group using three methods of magnetic field exposure assessment. ${ }^{\text {a }}(95 \%$ Cl = confidence interval)

\begin{tabular}{|c|c|c|c|c|c|c|c|c|c|}
\hline & \multicolumn{3}{|c|}{ Alzheimer's disease } & \multicolumn{3}{|c|}{ Amyotrophic lateral sclerosis } & \multicolumn{3}{|c|}{ Parkinson's disease } \\
\hline & Cases & $\begin{array}{c}\text { Adjusted } \\
\text { OR }\end{array}$ & $95 \% \mathrm{Cl}$ & Cases & $\begin{array}{c}\text { Adjusted } \\
\text { OR }\end{array}$ & $95 \% \mathrm{Cl}$ & Cases & $\begin{array}{c}\text { Adjusted } \\
\text { OR }\end{array}$ & $95 \% \mathrm{Cl}$ \\
\hline \multicolumn{10}{|l|}{ Method 1} \\
\hline Nonelectrical & 1503 & 1.00 & . & 293 & 1.00 & . & 1430 & 1.00 & . \\
\hline Electrical & 53 & 1.05 & $0.71-1.56$ & 19 & 2.30 & $1.29-4.09$ & 47 & 1.55 & $0.98-2.45$ \\
\hline \multicolumn{10}{|l|}{ Method $2^{b}$} \\
\hline No exposure & 1209 & 1.00 & . & 242 & 1.00 & . & 1141 & 1.00 & . \\
\hline Possible exposure & 285 & 1.15 & $0.95-1.39$ & 51 & 1.18 & $0.83-1.67$ & 272 & 1.17 & $0.96-1.42$ \\
\hline Definite or probable exposure & 62 & 1.21 & $0.83-1.76$ & 19 & 1.75 & $1.00-3.06$ & 64 & 1.76 & $1.17-2.65$ \\
\hline \multicolumn{10}{|l|}{ Method 3} \\
\hline$<0.10 \mu \mathrm{T}$ & 218 & 1.00 & . & 59 & 1.00 & . & 202 & 1.00 & . \\
\hline $0.10-0.19 \mu \mathrm{T}$ & 786 & 0.95 & $0.76-1.19$ & 134 & 0.79 & $0.54-1.15$ & 739 & 1.16 & $0.92-1.45$ \\
\hline $0.20-0.29 \mu \mathrm{T}$ & 229 & 0.83 & $0.63-1.10$ & 51 & 1.21 & $0.75-1.93$ & 216 & 1.04 & $0.78-1.37$ \\
\hline$\geq 0.30 \mu \mathrm{T}$ & 73 & 1.01 & $0.68-1.49$ & 12 & 0.77 & $0.37-1.59$ & 88 & 1.50 & $1.02-2.19$ \\
\hline Unknown & 250 & 0.99 & $0.75-1.31$ & 56 & 0.83 & $0.52-1.31$ & 232 & 1.02 & $0.77-1.36$ \\
\hline
\end{tabular}


was used to assess the exposure. Most of the elevated risk for amyotrophic lateral sclerosis in methods 1 and 2 was due to electrical or electronic technicians and engineers, job titles assigned geometric mean exposure values that were relatively low $(0.19-0.26 \mu \mathrm{T})$.

The most consistent associations with estimated magnetic-field exposure across the methods of exposure assessment were found for Parkinson's disease (table 2). The use of a tiered system of estimated exposure (method 2) provided the strongest evidence of an association. The adjusted odds ratio for combinations of job title and industry with definite or probable magnetic-field exposure was 1.76 (95\% CI 1.17-2.65). A review of nonelectrical magnetic-field-related occupations used in method 2 found welders to be overrepresented among the Parkinson's disease deaths. We observed 12 welders with Parkinson's disease versus 6 welders among the referents (adjusted OR 2.26, 95\% CI 0.85-6.06). When the job-exposure matrix was used, persons in the highest exposure category had an elevated odds ratio (adjusted OR 1.50, 95\% CI 1.02-2.19), but there was no evidence of a trend by exposure level.

The definition of the high-exposure job titles differed according to the different exposure assessment methods used. Table 3 lists the 15 electrical job titles traditionally considered to have high magnetic-field exposure and their corresponding geometric means from the job-exposure matrix. Some of these job titles, such as electric power installers or repairers and power plant operators, were assigned high exposure values. However, several titles within this group had considerably lower values and ranked relatively low when compared with other job titles represented in the Alzheimer's disease case-referent study. Four of these electrical occupations for which there were adequate data did not fall into the top two tiers of estimated exposure according to the job-exposure matrix $(0.20-0.29 \mu \mathrm{T}$ and $\geq 0.3 \mu \mathrm{T})$. Of the 15 job titles with the highest geometric mean assigned by the job-exposure matrix, only 6 were included among the electrical occupations (data not shown). The two occupations in the case-referent study on Alzheimer's disease with magnetic-field-exposure estimates higher than any of the electrical occupations were textile sewing machine operators $(2.99 \mu \mathrm{T})$ and welders $(0.95 \mu \mathrm{T})$.

Nevertheless, the overall estimates of magnetic-field intensity using the job-exposure matrix correlated well with the other methods of exposure assessment. For the Alzheimer's disease case-referent group, the mean jobexposure matrices for electrical versus nonelectrical workers (method 1 ) were $0.40 \mu \mathrm{T}$ and $0.15 \mu \mathrm{T}$, respectively. The mean job-exposure matrices for persons in the three tiers of exposure based on job title and industry (method 2) were $0.47,0.20$, and $0.14 \mu \mathrm{T}$. The occupational grouping of service or labor and others used in the social class variable also had higher overall estimates of magnetic-field exposure when the job-exposure matrix was used. Eleven of the fifteen electrical occupations were included in this broad occupational category, and the mean of the job-exposure matrices assigned to persons in this group was $0.18 \mu \mathrm{T}$ versus $0.13 \mu \mathrm{T}$ for the professional and managerial group.

\section{Discussion}

Previous reports suggested an association between amyotrophic lateral sclerosis and occupations with potential magnetic-field exposure. In a clinic-based study of patients with amyotrophic lateral sclerosis, odds ratios of 7.5 and 5.5 were found for the upper quartiles of magnetic-field exposure when total occupational exposure and average occupational exposure, respectively, were used (3). A review of occupational data from five electric utilities found an association between magnetic fields and amyotrophic lateral sclerosis deaths, particularly for exposures of long duration (2). A study of diseases of the central nervous system among a cohort of former Danish utility workers reported an increase in the standardized incidence ratio for motor neuron

Table 3. Geometric mean magnetic field values and rank of electrical occupations based on the job-exposure matrix and their ranking among all occupations observed in the Alzheimer's disease case-referent study.

\begin{tabular}{|c|c|c|}
\hline Job Title a & $\begin{array}{l}\text { Geometric } \\
\text { mean }(\mu \mathrm{T})^{b}\end{array}$ & Rank $^{c}$ \\
\hline Electric power installers and repairers (577) & 0.94 & 3 \\
\hline Power plant operators (695) & 0.78 & 4 \\
\hline Motion picture projectionists (773) & 0.63 & 7 \\
\hline Electricians (575) & 0.55 & 9 \\
\hline Electrician apprentices (576) & 0.55 & 9 \\
\hline $\begin{array}{l}\text { Miscellaneous electrical and electronic } \\
\text { equipment repairers (533) }\end{array}$ & 0.47 & 11 \\
\hline Electrical and electronic technicians (213) & 0.26 & 24 \\
\hline $\begin{array}{l}\text { Electronic repair, communication, and } \\
\text { industrial equipment }(523)\end{array}$ & 0.24 & 28 \\
\hline $\begin{array}{l}\text { Household appliance and power } \\
\text { tool repairers }(526)\end{array}$ & 0.23 & 41 \\
\hline Electrical and electronic engineers (055) & 0.19 & 71 \\
\hline Telephone line installers and repairers (527) & 0.17 & 87 \\
\hline Telephone installers and repairers (529) & 0.14 & 129 \\
\hline Data processing equipment repairers (525) & 0.09 & 198 \\
\hline Broadcast equipment operators $(228)^{d}$ &.$\cdot$ &.$\cdot$ \\
\hline $\begin{array}{l}\text { Supervisors of electricians and power } \\
\text { installers and repairers }(555)^{d}\end{array}$ & .. &.. \\
\hline
\end{tabular}

a Code of the Bureau of Census Classified Index of Occupations and Industry in parentheses.

b Time-weighted average geometric mean based on job-exposure matrix.

c Exposure ranking of electrical occupations among all job titles

represented in the Alzheimer's disease case-referent study.

d The job-exposure matrix used in this study did not contain data on the geometric means for these job titles. 
disease (6). Each of these recent studies utilized assessments of magnetic-field exposure specific to job title and duration of employment. Three case-referent studies have also identified electrical occupations as a risk factor for amyotrophic lateral sclerosis $(1,4,16)$.

Persons with electrical occupations may, however, have greater potential for electric shock events. Three case-referent studies reported history of electrical shock as a specific trauma associated with amyotrophic lateral sclerosis $(4,17,18)$, although others failed to support this relationship (19). In our study, the moderate risk for electrical occupations was no longer evident when the persons were assigned to categories of estimated magnetic-field exposure based on the job exposure matrix. These findings support the hypothesis that electric shock or another unidentified variable associated with electrical occupations, rather than magnetic-field exposure, was responsible for the observed associations with amyotrophic lateral sclerosis.

Our findings do not support an association between occupational magnetic-field exposure and Alzheimer's disease when exposure is classified by electrical work $(\operatorname{method} 1)$ or the job-exposure matrix $(\operatorname{method} 3)$. In a recent series of studies, risk estimates for this association ranged from 2.9 to 3.9 , and they were particularly influenced by sewing occupations $(7,8)$. We were unable to corroborate an association with sewing machine work in this analysis since there were inadequate numbers of men with these job titles in our study population. A Swedish study with more quantitative exposure assessment found a higher risk (OR 2.4 and 2.7) for Alzheimer's disease among subjects whose most recent job had an average magnetic-field exposure of more than $0.2 \mu \mathrm{T}$ (9). Schulte et al (20) suggested an association between occupations with probable magnetic-field exposure and Alzheimer's disease mortality based on death certificates in over 27 states from 1982 to 1991. Although not hypothesized a priori, an occupational clustering of electrical workers with Alzheimer's disease was found, particularly for electricians, power transmitter installers, electrical and electronic technicians, broadcast operators, and electrical and electronic engineers (21). Savitz et al (1) reported a slightly elevated risk for Alzheimer's disease among persons with electrical occupations (OR 1.2, 95\% CI 1.0-1.4), the strongest association being observed for electricians and power plant operators. The first 5 years of our data partially overlapped with this multistate case-referent study (1), but with approximately one-fifth the number of exposed cases we did not have adequate power to detect an elevation in risk of this magnitude. Finally, two cohort studies failed to find elevated risks for Alzheimer's disease deaths among electric utility workers $(2,6)$, although one analysis demonstrated a modest, yet imprecise, rate ratio of 2.1 for persons with magnetic-field-exposed jobs for more than 20 years (2). We were unable to evaluate the duration of employment with our data.

We found consistent evidence of an association between Parkinson's disease and history of electrical and other magnetic-field-related occupations using each of the three methods of exposure assessment, but these findings must be considered within the context of previous studies that have assessed this potential relationship. Two retrospective cohort studies $(2,6)$ and a death certificate-based case-referent study (1) failed to find an association between Parkinson's disease and occupational magnetic-field exposure. However, the death-certificate-based study found modest risks for power plant operators and telephone installers and repairers (1). We did not have adequate data to assess these specific occupations, but we found that welders accounted for some of the observed risk for Parkinson's disease when two of our exposure assessment methods were used. Welders are exposed to high levels of magnetic fields (22), as well as other potentially neurotoxic agents such as metals, and our findings agree with previous observations of an association between welding and a risk of Parkinson's disease $(10,23)$.

The primary limitation of this study was the inherent inaccuracy associated with the use of death certificates in collecting disease and exposure data. This problem is particularly apparent when neurological disorders with complex case definitions and a high potential for misdiagnosis are considered. Among the three diseases of concern in this study, amyotrophic lateral sclerosis has been accurately reported in at least $87 \%$ of cases $(24,25)$. In contrast, Alzheimer's disease and Parkinson's disease are disorders of long duration, and patients are likely to die of unrelated primary causes. The reporting accuracy for these two diseases was shown to be $60 \%$ to $65 \%$ for any mention on death certificates $(26,27)$, but recent trends suggest better reporting for neurodegenerative conditions (28).

Associations with social class and race have been described for several neurodegenerative diseases, especially Alzheimer's disease, and they existed in this population as well (data not shown). Professional and managerial workers, who are less likely to have magneticfield exposure, were more likely to have these diseases listed on their death certificates. This finding is contrary to reports that higher education and socioeconomic status is protective for Alzheimer's disease (29-31), suggesting that the elevated reporting of these diseases for the professional and managerial occupations in our population may reflect, in part, diagnostic sensitivity bias rather than true risk. Thus we cannot rule out the possibility that the odds ratios presented in table 2 suffer from ascertainment bias and underestimate the risk between these diseases and occupational magnetic-field exposure. 
The validity of this study was also dependent upon the accurate recording of occupational data on death certificates. Occupations reported on death certificates have been found to be in agreement with next-of-kin interview or employment records $48 \%$ to $76 \%$ of the time (32-35). White males, comprising over $97 \%$ of our study population, had the highest rate of accuracy for occupational reporting (33). In a study of brain cancer and magnetic-field exposure among utility workers, the accuracy of death certificate coding for exposed occupations was low overall but similar to that for unexposed occupations, and the concordance rates ranged from $54 \%$ to $80 \%$ for lineman, electricians, power plant operators, mechanics, and welders (35). Reporting accuracy of industry on death certificates, a variable used in one of our exposure assessment methods, ranged from $67 \%$ to $75 \%$ in previous studies (33-35). Furthermore, death certificate reporting of job titles and industry was restricted to the subject's primary occupation and was limited by the lack of data for duration of employment. Exposure misclassification due to the lack of historical information on individual occupations and the recognized limitations in death certificate reporting of job title and industry would bias the risk estimates toward the null.

In this paper we have shown that the findings for associations between neurodegenerative diseases and magnetic-field exposure are sensitive to the method of exposure assessment used. The grouping of electrical occupations (method 1) as the means of identifying persons having probable occupational magnetic-field exposure has been used in several studies $(1,12,13)$. However, this grouping of occupations is not specific with regard to any particular exposure of interest. The use of multiple exposure levels based on job title and industry (method 2) captured additional nonelectrical occupations that had been classified as unexposed, but these exposure categories still included several job titles that would not be described as highly exposed when magnetic-field measurements are evaluated in the occupational setting. The job-exposure matrix (method 3) identified discrepancies between several hypothetically highexposure electrical occupations and their respective magnetic-field measurements and suggested that the other methods contributed additional misclassification of high-exposure nonelectrical occupations.

This study provides some support for an association between occupational magnetic-field exposure and Parkinson's disease. In view of the fact that associations between magnetic-field exposure and Parkinson's disease have not been described previously, this observation requires replication. The associations with the other neurodegenerative diseases studied were inconsistent and dependent on the method of exposure assessment. Future studies will need to be designed carefully to assure that the methods of exposure assessment used provide an accurate assessment of each subject's true exposure.

\section{Acknowledgments}

The authors thank Carol Garrett and Katy Meng of the Colorado Department of Environment and Health for their assistance in acquiring the death certificate records.

\section{References}

1. Savitz DA, Loomis DP, Tse CJ. Electrical occupations and neurodegenerative disease: analysis of US mortality data. Arch Environ Health 1998;53(1):71-4.

2. Savitz DA, Checkoway H, Loomis DP. Magnetic field exposure and neurodegenerative disease mortality among electric utility workers. Epidemiology 1998;9(4):398-404.

3. Davanipour Z, Sobel E, Bowman J. Amyotrophic lateral sclerosis and occupational exposure to EMFs. Bioelectromagnetics 1997;18:28-35.

4. Deapen DM, Henderson BE. A case-control study of amyotrophic lateral sclerosis. Am J Epidemiol 1986;123(5):790-9.

5. Johansen C, Olsen C. Mortality from amyotrophic lateral sclerosis, other chronic disorders, and electric shocks among utility workers. Am J Epidemiol 1998;148(4):362-8.

6. Johansen C. Exposure to electromagnetic fields and risk of central nervous system disease in utility workers. Epidemiology 2000;11:539-43.

7. Sobel E, Davanipour Z, Sulkava R, Erkinjuntti T, Wilkstrom $\mathrm{J}$, Henderson V, et al. Occupations with exposure to electromagnetic fields: a possible risk factor for Alzheimer's disease. Am J Epidemiol 1995;142:515-24.

8. Sobel E, Dunn M, Davanipour Z, Qian Z, Chui HC. Elevated risk of Alzheimer's disease among workers with likely exposure to electromagnetic field exposure. Neurology 1996;47:1477-81.

9. Feychting M, Pedersen NL, Svedberg P, Floderus B, Gatz M. Dementia and occupational exposure to magnetic fields. Scand J Work Environ Health 1998;24(1):46-53.

10. Wechsler LS, Checkoway H, Franklin GM, Costa LG. A pilot study of occupational and environmental risk factors for Parkinson's disease. Neurotoxicology 1991;12:387-92.

11. United States Department of Commerce, Bureau of the Census. 1980 census of the population: classified index of industries and occupations. Washington (DC): Government Printing Office, 1980.

12. Loomis DP, Savitz DA. Mortality from brain cancer and leukaemia among electrical workers. Br J Ind Med 1990;47:633-8.

13. Milham S. Mortality in workers exposed to electromagnetic fields. Environ Health Perspect 1985;62:297-300.

14. Lin RS, Dischinger PC, Conde J, Farrell KP. Occupational exposure to electromagnetic fields and the occurrence of brain tumors: an analysis of possible associations. J Occup Med 1985;276:413-9.

15. Speers MA, Dobbins JG, Miller VS. Occupational exposures 
and brain cancer mortality: a preliminary study of East Texas residents. Am J Ind Med 1988;13:629-38.

16. Gunnarsson L, Bodin L, Soderfeldt B, Axelson O. A casecontrol study of motor neurone disease: its relation to heritability, occupational exposures, particularly to solvents. Br J Ind Med 1992;49:791-8.

17. Gawel M, Zaiwalla Z, Rose FC. Antecedent events in motor neuron disease. J Neurol Neurosurg Psychiatry 1983;46:1041-3.

18. Gallagher JP, Sanders M. Trauma and amyotrophic lateral sclerosis: a report of 78 patients. Acta Neurol Scand 1987;75(2):145-50.

19. Kondo K, Tsubaki T. Case-control studies of motor neuron disease. Arch Neurol 1981;38:220-6.

20. Schulte PA, Burnett CA, Boeniger MF, Johnson J. Neurodegenerative diseases: occupational occurrence and potential risk factors. Am J Public Health 1996;86:1281-8.

21. Schulte PA, Burnett CA. EMFs and Alzheimer's disease (letter). Neurology 1997;49:312.

22. Bracken TD, Patterson RM. Variability and consistency of electric and magnetic field occupational exposure measurements. J Exp Anal Environ Epidemiol 1996;6:355-74.

23. Racette BA, McGee-Minnich L, Moerlein SM, Mink JW, Videen TO, Perlmutter JS. Welding-related parkinsonism: clinical features, treatment, and pathophysiology. Neurology 2001;56:8-13.

24. Juergens SM, Kurland LT, Okazaki H, Mulder DW. ALS in Rochester, Minnesota, 1925-1977. Neurology 1980;30:46370.

25. Kurtzke JF, Beebe GW. Epidemiology of amyotrophic lateral sclerosis: a case-control comparison based on ALS deaths. Neurology 1980;30:453-62.

26. Olichney JM, Hofstetter CR, Galasko D, Thal LJ, Katzman R. Death certificate reporting of dementia and mortality in an Alzheimer's disease research center cohort. J Am Geriatr Soc
1995;43:890-3.

27. Raiford K, Anton-Johnson S, Haycox Z, Nolan K, Schaffer A, Caimano $C$, et al. CERAD part VII: accuracy of reporting dementia on death certificates of patients with Alzheimer's disease. Neurology 1994;44:2208-9.

28. Hoyert DL, Rosenberg HM. Mortality from Alzheimer's disease: an update. Hyattsville (MD): National Center for Health Statistics, 1999. National vital statistics reports.

29. Stern Y, Gurland B, Tatemichi TK, Tang MX, Wilder D, Mayeux R. Influence of education and occupation on the incidence of Alzheimer's disease. JAMA 1994;271:100410.

30. The Canadian Study of Health and Aging. The Canadian study of health and aging: risk factors for Alzheimer's disease in Canada. Neurology 1994;44:2073-80.

31. Launer LJ, Andersen K, Dewey ME, Letenneur L, Ott A, Amaducci LA, et al. Rates and risk factors for dementia and Alzheimer's disease: results from EURODEM pooled analysis. Neurology 1999;52:78-84.

32. Swanson GM, Schwartz AG, Burrows RW. An assessment of occupation and industry data from death certificates and hospital medical records for population-based cancer surveillance. Am J Public Health 1984;74(5):464-7.

33. Steenland K, Beaumont J. The accuracy of occupational and industry data on death certificates. J Occup Med 1984;26(4):288-96.

34. Schumacher MC. Comparison of occupation and industry information from death certificates and interviews. Am J Public Health 1986;76(6):635-7.

35. Andrews KW, Savitz DA. Accuracy of industry and occupation on death certificates of electric utility workers: implications for epidemiologic studies of magnetic fields and cancer. Bioelectromagnetics 1999;20:512-8.

Received for publication: 25 January 2001 